\title{
SHARP MEAN TRIANGLE INEQUALITY
}

\author{
Masatoshi Fujil, Mikio Kato, Kichi-Suke Saito \\ AND TAKAYUKI TAMURA
}

\begin{abstract}
By using a mean operator we shall present some sharp mean triangle inequalities in a Banach space which generalize the sharp triangle inequality with $n$ elements and its reverse one shown recently by the last three authors in [7]. In the course of doing this we shall present a new two element triangle inequality with parameter and its reverse. Several applications will be given.
\end{abstract}

Mathematics subject classification (2010): 46B20, 46B25.

Keywords and phrases: triangle inequality, mean.

\section{REFERENCES}

[1] J. B. Diaz And F. T. MetCALF, A complementary triangle inequality in Hilbert and Banach spaces, Proc. Amer. Math. Soc., 17 (1966), 88-97.

[2] S. S. Dragomir, Reverses of the triangle inequality in Banach spaces, J. Inequal. Pure and Appl. Math., 6, 5 (2005), Art. 129, pp. 46.

[3] S. S. Dragomir, Generalizations of the Pećarić-Rajić inequality in normed linear spaces, Math. Inequal. Appl., 12 (2009), 53-65.

[4] C. F. DunKL And K. S. Williams, A simple norm inequality, Amer. Math. Monthly, 71 (1964), $53-54$.

[5] C.-Y. Hsu, S.-Y. Shaw AND H.-J. Wong, Refinements of generalized triangle inequalities, J. Math. Anal. Appl., 344 (2008), 17-31.

[6] H. HudZiK And T. R. Landes, Characteristic of convexity of Köthe function spaces, Math. Ann., 294 (1992), 117-124.

[7] M. KATO, K.-S. SAITO AND T. TAMURA, Sharp triangle inequality and its reverse in Banach spaces, Math. Inequal. Appl., 10 (2007), 451-460.

[8] L. Maligranda, Simple norm inequalities, Amer. Math. Monthly, 113 (2006), 256-260.

[9] K.-I. Mitani, K.-S. SAito, M. Kato AND T. TAMURA, On sharp triangle inequalities in Banach spaces, J. Math. Anal. Appl., 336 (2007), 1178-1186.

[10] J. L. MASSERA AND J. J. SCHÄFFER, Linear differential equations and functional analysis I, Ann. of Math., 67 (1958), 517-573.

[11] J. PEČARIĆ AND R. RAJIĆ, The Dunkl-Williams inequality with $n$ elements in normed linear spaces, Math. Inequal. Appl., 10 (2007), 461-470.

[12] S. SAitoh, Generalizations of the triangle inequality, J. Inequal. Pure Appl. Math., 4, 3 (2003), Art. 62, pp. 5.

[13] W. TaKahashi, Nonlinear Functional Analysis, Yokohama Publishers, Yokohama, 2000. 